Si gnal ing mechani sns for posi tive and negat i ve regul at i on of cell notility by sphi ngosi ne-1- phosphat e recept or s

\begin{tabular}{|l|l|}
\hline 著者 & $\begin{array}{l}\text { Takuwa Yoh, Sugi not o Naot oshi, Takuwa Nor i ko, } \\
\text { I gar ashi Yasuyuki }\end{array}$ \\
\hline $\begin{array}{l}\text { j our nal or } \\
\text { publ i cat i on ti tl e }\end{array}$ & Sphi ngol i pi d Bi ol ogy \\
\hline vol une & 2006 \\
\hline page range & $415-425$ \\
\hline year & $2006-01-01$ \\
\hline URL & ht t p: //hdl . handl e. net/2297/39034 \\
\hline
\end{tabular}




\section{Signaling mechanisms for positive and negative regulation of cell motility by sphingosine-1-phosphate receptors}

Yoh Takuwa, Naotoshi Sugimoto, Noriko Takuwa and Yasuyuki Igarashi

Department of Physiology, Kanazawa University Graduate School of Medicine, 2-6-11 Takara-machi, Kanazawa 920-8640, and Department of Biomembrane and Bifunctional Chemistry, Hokkaido University Graduate School of Pharmacology, Sapporo 060-0812, Japan

\section{Introduction}

Sphingosine-1-phosphate (S1P) is a lysophospholipid growth factor circulating in blood, which induces a wide variety of biological responses in diverse cell types. S1P is present at $10^{-7} \mathrm{M}$ order of concentration in the blood largely in a form bound to plasma proteins including albumin and lipoproteins, and released by activated platelets and other cell types [1]. Identification of cell surface receptors for S1P provided strong support for the notion that many, if not all, of the diversity of biological activities of S1P are mediated through either of these receptors [2-5]. Among 5 S1P receptor subtypes, $\mathrm{S}_{1} \mathrm{P}_{1} / \mathrm{Edg}$ (for endothelial differentiation gene)-1, $\mathrm{S}_{2} \mathrm{P}_{2} / \mathrm{Edg} 5, \mathrm{~S}_{1} \mathrm{P}_{3} / \mathrm{Edg} 3$, are widely expressed in various tissues [2-5].

Cell migration is a critical component of cellular responses, which is involved in such diverse physiological and pathological processes as embryonic morphogenesis, 
angiogenesis, wound healing, atherogenesis, inflammation and tumor cell dissemination [6]. Cell migration is regulated in both positive and negative directions by a variety of extracellular cues called chemoattractants and chemorepellants, respectively. A number of biologically active substances, including chemokines, cytokines and growth factors, have been demonstrated to act as chemoattractants to induce chemotaxis, i.e. cell migration directed toward a higher concentration of a chemoattractant. Certain factors including some members of the semaphorine and the ephrine families were shown to directly repel neuronal and vascular cells as chemorepellants. However, our knowledge about chemorepellants or migration-inhibitory substances is generally much limited at present, compared to chemoattractants [6].

More than 10 years ago, Igarashi and his colleagues demonstrated for the first time that S1P exerted inhibitory effects on migration and invasion of certain tumor cells including melanoma cells and osteosarcoma cells [7]. They also showed that S1P inhibited migration of vascular smooth muscle cells (VSMCs) [8] and neutrophils [9] that were directed toward chemoattractants. More recently, it was shown that S1P by itself was capable of stimulating, rather than inhibiting, chemotaxis of vascular 
endothelial cells [10] and mouse embryonic fibroblasts [11]. Thus, S1P appeared to be a unique, bimodal regulator of cell migration.

In this chapter we describe molecular mechanisms underlying this bimodal regulation by S1P, i.e. S1P receptor subtype-specific, positive and negative regulation of cell motility and the Rho family GTPases, and S1P regulation of invasion and metastasis of malignant melanoma cells via endogenous S1P receptor through the control of Rho GTPases.

\section{Receptor subtype-specific, bimodal regulation of cell motility and the}

\section{small GTPase Rac by S1P}

After the identification of the S1P-specific Edg family receptors, S1P was found to stimulate chemotaxis in vascular endothelial cells via endogenously expressed $\mathrm{S}_{1} \mathrm{P}_{1}$ and $\mathrm{S} \mathrm{P}_{3}[10,11]$. However, it remained unknown how S1P induced inhibition of cell migration in several other cell types, although an extracellular mode of this inhibitory S1P action was suggested [12]. We showed the activity of each of the S1P receptors on cell migration in Boyden chamber assay by employing Chinese hamster ovary (CHO) 
cells that stably overexpressed each of the widely expressed subtypes, $\mathrm{S}_{1} \mathrm{P}_{1}, \mathrm{~S}_{1} \mathrm{P}_{2}$ and $\mathrm{S} 1 \mathrm{P}_{3}$. It is known that $\mathrm{CHO}$ cells overexpressing exogenous chemoattractant receptors can vigorously respond to a concentration gradient of a respective chemoattractant with stimulation of directed cell migration in a trans-well migration assay. S1P stimulated directed cell migration, i.e. chemotaxis, of either $\mathrm{S}_{1} \mathrm{P}_{1}$ - or $\mathrm{S}_{1} \mathrm{P}_{3}$-expressing $\mathrm{CHO}$ cells $[13,14]$. These two cell types were quite sensitive to S1P with the threshold concentrations as low as $0.1-1 \mathrm{nM}$ of S1P. It was also reported that S1P stimulated chemotaxis in HEK293 cells overexpressing S1P ${ }_{1}$ [15]. In sharp contrast, S1P did not stimulate trans-well migration of $\mathrm{S}_{1} \mathrm{P}_{2}$-expressing cells and vector-transfected control cells [13]. However, the addition of a potent chemoattractant insulin-like growth factor (IGF-I) unveiled a strong inhibitory effect of S1P on cell migration via $\mathrm{S}_{2} \mathrm{P}_{2}$; IGF-I stimulated chemotaxis in three S1P receptor subtype-expressing cells and vector control cells to comparable degrees. When S1P was present together with IGF-I in the lower well of Boyden chamber, IGF-I-directed chemotaxis was completely abolished only in $\mathrm{S}_{1} \mathrm{P}_{2}$-expressing $\mathrm{CHO}$ cells. The $\mathrm{S}_{1} \mathrm{P}_{2}$-mediated inhibitory effect of $\mathrm{S} 1 \mathrm{P}$ on cell migration was potent with the threshold concentration of as low as $1 \mathrm{nM}$, and was 
dependent on an S1P concentration gradient. Thus, S1P acts as a chemorepellent.

Chemoattractants receptors activate complex, multiple signaling cascades including protein tyrosine kinases, lipid kinases and the low molecular weight GTPases [6]. These signaling events lead in concert to regulate actin organization and myosin motor function, which constitute essential processes for cell migration. Among the low molecular weight G proteins, the Rho family GTPases comprise three major members, Rho, Rac and Cdc42, and exert distinct regulatory actions on actin cytoskeletons, thus playing an important role in cell motility [16 17]; Rho mediates formation of stress fibers and focal adhesions, while Rac and Cdc42 direct peripheral actin assembly that results in formation of lamellipodia and filopodia, respectively, especially at the leading edge of a migrating cell. For example, expression of a dominant negative form of Rac, $\mathrm{N}^{17}$-Rac, in a variety of cell types inhibits directed cell migration toward diverse chemoattractants, including PDGF, LPA, epidermal growth factor (EGF), insulin and colony stimulating factor-1 [16-18], indicating that Rac is required for chemotaxis toward these attractants. The expression of dominant negative forms of the Rho family GTPases, $\mathrm{N}^{17}$-Rac and $\mathrm{N}^{17}$-Cdc42, but not $\mathrm{N}^{19}$-RhoA, inhibited chemotaxis toward S1P 
in $\mathrm{S}_{1} \mathrm{P}_{1}$ - and $\mathrm{S}_{1} \mathrm{P}_{3}$-expressing $\mathrm{CHO}$ cell types and IGF-I in all the $\mathrm{CHO}$ cell types, indicating that IGF-I- and S1P-directed chemotaxis was dependent on Rac and Cdc42 [13]. S1P as well as IGF-I increased an amount in a GTP-bound, active form of Rac in

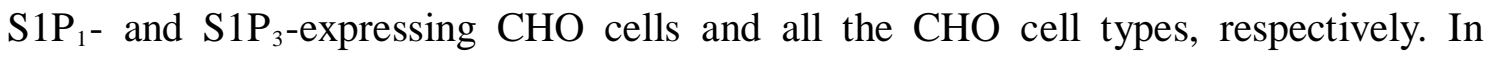

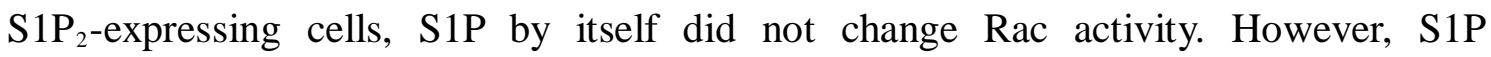
dramatically abolished IGF-I-induced Rac activation and lamellipodia formation with a dose-response relationship similar to that for S1P inhibition of IGF-I-directed chemotaxis [13]. Either S1P or IGF-I did not affect GTP-loading of Cdc42 in any of CHO cell types. Rho regulation by S1P and IGF-I was a little complicated; stimulation of the attractant receptor $\mathrm{S}_{1} \mathrm{P}_{1}$ did not change RhoA activity, but both the repellant receptor $\mathrm{S}_{1} \mathrm{P}_{2}$ and the attractant $\mathrm{S}_{1} \mathrm{P}_{3}$ stimulated RhoA. IGF-I did not affect RhoA or Cdc42 activity [13]. Thus, all these data in CHO cells was consistent with the notion that stimulation of Rac activity, but not of Cdc42 or RhoA, above the resting level was necessary for stimulation of chemotaxis in this cell type. The three Edg family S1P receptors transmit overlapping but distinct sets of signals to the Rho family GTPases $[13,14,19,20]$, thus allowing receptor subtype-specific, distinct regulatory activities on 
cell migration (Fig. 1).

Chemoattractants that act via $G$ protein-coupled receptors are generally shown to mediate chemotaxis and Rac activation via the heterotrimeric $G_{i}$ protein. However, signaling mechanisms of chemorepellant receptors were largely unknown. The C-terminal mini-peptide of the heterotrimeric $\mathrm{G}$ protein $\alpha$-subunits ( $\mathrm{G} \alpha$-CTs) serve as inhibitors specific for respective $G$ proteins [21]. The expression of either $G_{12} \alpha$-CT or $\mathrm{G}_{13} \alpha-\mathrm{CT}$, but not $\mathrm{G}_{\mathrm{s}} \alpha-\mathrm{CT}$ or $\mathrm{G}_{\mathrm{q}} \alpha-\mathrm{CT}$ or pertussis toxin, abrogated $\mathrm{S}_{1} \mathrm{P}_{2}$-mediated inhibition of Rac and cell migration. Moreover, either $S 1 P_{2}-G_{12 \alpha}$ or $S 1 P_{2}-G_{13 \alpha}$ fusion receptor [22], but not $\mathrm{S}_{1} \mathrm{P}_{2}-\mathrm{G}_{\mathrm{q \alpha}}$ fusion receptor, mediated $\mathrm{S} 1 \mathrm{P}$ inhibition of Rac and cell motility [14]. Our data indicated that the $\mathrm{G}_{12 / 13}$ family protein coupled $\mathrm{S}_{1} \mathrm{P}_{2}$ to inhibition of Rac, cell migration and lamellipodia in CHO cells [14]. Furthermore we found that downstream of $\mathrm{G}_{12 / 13}$, Rho mediated $\mathrm{S}_{1} \mathrm{P}_{2}$ inhibition of Rac and cell migration through a mechanism not involving Rho kinase as a Rho effector [14]. Very recently, Sanchez et al. [23] showed that $\mathrm{S} \mathrm{P}_{2}$ mediated inhibition of cell migration through stimulating the 3'-phosphatase of phosphoinositides, PTEN, in a Rho kinase-dependent manner. This may suggest the possibility that more than a single 
mechanism could contribute to $\mathrm{S}_{1} \mathrm{P}_{2}$ mediated inhibition of cell migration and that the mechanism behind $\mathrm{S}_{1} \mathrm{P}_{2}$-mediated cell migration inhibition may be different among cell types.

$\mathrm{S} 1 \mathrm{P}_{3}$ mediated Rac activatin and chemotaxis despite stimulating Rho [13]. We found in pertussis toxin-pretreated $\mathrm{CHO}$ cells expressing $\mathrm{S}_{1} \mathrm{P}_{3}$ that $\mathrm{S} 1 \mathrm{P}$ induced inhibition of Rac, cell migration and lamellipodia just as in $\mathrm{CHO}$ cells expressing $\mathrm{S}_{1} \mathrm{P}_{2}$ [14]. Thus, inactivation of $\mathrm{G}_{\mathrm{i}}$ by pertussis toxin treatment converted $\mathrm{S}_{1} \mathrm{P}_{3}$ into the $\mathrm{S}_{1} \mathrm{P}_{2}$-like repellant receptor. These results indicate that integration of counteracting signals from the $G_{i^{-}}$and the $G_{12 / 13}$-Rho pathways directs either positive or negative regulation of Rac and thus cell migration, upon activation of a single S1P receptor isoform.

\section{Stimulation and inhibition of melanoma cell invasion and metastasis by}

\section{S1P receptors}

Igarashi and his colleagues [7] first reported that S1P inhibits trans-well migration as well as invasion across the Matrigel layer of B16 mouse melanoma cells. They showed that S1P immobilized on glass beads exhibited similar inhibitory action on migration of 
B16 melanoma cells [12]. They also demonstrated the presence of a single class of specific, binding site for a radio-labelled S1P on B16 melanoma cells. These observations suggested that S1P inhibited melanoma cell migration through an extracellular action by specific binding to a cell surface receptor. On the other hand, other studies suggested S1P-induced migration inhibition through its intracellular action [24]. Our observation that the heterologous expression of $\mathrm{S} \mathrm{P}_{2}$ mediated cell migration inhibition in $\mathrm{CHO}$ cells prompted us to investigate the possibility that $\mathrm{S}_{1} \mathrm{P}_{2}$ receptor might mediate migration inhibition of B16 melanoma cells in response to S1P. We found that B16 melanoma cells detectably expressed $\mathrm{S}_{1} \mathrm{P}_{2}$, but not other $\mathrm{S} 1 \mathrm{P}$ receptor subtypes [25]. The $\mathrm{S}_{2} \mathrm{P}_{2}$-selective antagonist JTE013, which specifically blocks S1P binding to $\mathrm{S}_{1} \mathrm{P}_{2}$ and prevents $\mathrm{Ca}^{2+}$ mobilization and ERK activation mediated by $\mathrm{S}_{2} \mathrm{P}_{2}$, completely abolished the inhibitory effect of S1P on B16 cell migration. Thus, B16 melanoma cell is the example of inhibitory regulation of cell migration by endogenously expressed $\mathrm{S}_{1} \mathrm{P}_{2}$.

In B16 cells, S1P inhibited and stimulated Rac and RhoA, respectively, as in $\mathrm{S}_{1} \mathrm{P}_{2}$-overexpressing $\mathrm{CHO}$ cells, and that both of these responses were totally abrogated 
by JTE013. S1P did not affect Cdc42 activity. Consistent with the observation in $\mathrm{S}_{1} \mathrm{P}_{2}$-expressing $\mathrm{CHO}$ cells [13], suppression of endogenous Rac activity by adenovirus-mediated expression of $\mathrm{N}^{17}$ Rac resulted in inhibition of migration of B16 cells [25]. On the other hand, the inactivation of cellular Rho by C3 toxin reversed S1P inhibition of migration in B16 cells. In addition, random migration activity of B16 cell in the absence of S1P was also stimulated, rather than inhibited, after C3 toxin pretreatment, suggesting that the basal Rho activity is inhibitory for cell migration. This latter observation is consistent with a previous report in Rat1 fibroblasts [18]. Similar to CHO cells, the Rho kinase inhibitors Y27632 or HA1077, at the concentrations that effectively inhibited stress fiber formation, did not reverse S1P inhibition of migration. The results indicate that a RhoA effector other than Rho kinase, and cell responses different from formation of stress fibers or focal adhesions, are responsible for mediating negative regulation of cell motility and invasion by S1P.

$\mathrm{S}_{1} \mathrm{P}_{2}$ also mediated inhibition of B 16 cell invasion across the Matrigel matrix, which is Rac-dependent [25]. With regard to the latter point, it is of note that Rac1 is reported to mediate matrix metalloproteinase (MMP)-2 activation in fibrosarcoma cells [26]. 
Requirement of Rac activity for both cell motility and invasion through extracellular matrix has been reported in Rat1 fibroblasts and T lymphoma cells as well [18]. Wang et al. [24] showing that S1P inhibited migration of MDA-MB-231 breast carcinoma cells which express $\mathrm{S}_{1} \mathrm{P}_{1}$ and $\mathrm{S}_{1} \mathrm{P}_{3}$ but not $\mathrm{S}_{2} \mathrm{P}_{2}$, and postulated that this $\mathrm{S} 1 \mathrm{P}$-inhibitory action of tumor cell migration was due to an intracellular action of S1P. It is possible that the role for Rac in regulation of migration or invasion might be distinct among cells of epithelial and non-epithelial origin through mechanisms involving the regulation of cell adhesion molecules. Invasion of $\mathrm{B} 16$ cells was inhibited by $\mathrm{N}^{17}$ Rac, like cell migration. On the other hand, unlike cell migration, invasion in the absence of S1P was inhibited by C3 toxin, suggesting that invasion is dependent upon both Rac and Rho. Inhibition of invasion by the expression of $\mathrm{N}^{17} \mathrm{RhoA}$, as well as $\mathrm{V}^{14} \mathrm{RhoA}$, was reported previously in fibroblasts [18]. Despite this, the inhibitory effect of S1P on B16 cell invasion was partially reversed by C3 toxin pretreatment, underscoring the role for Rho in S1P inhibition of invasion. These composite observations indicate that $\mathrm{S}_{1} \mathrm{P}_{2}$-mediated Rho stimulation and Rac inhibition are both involved as mechanisms for S1P-induced inhibition of B16 cell migration and invasion. However, Rho stimulation 
by itself doe not appear to be sufficient for migration inhibition in the absence of Rac inhibition. This notion is based on the observation obtained in $\mathrm{S}_{1} \mathrm{P}_{3}$-overexpressing $\mathrm{B} 16$ cells (see below), in which the addition of S1P together with JTE013 stimulated RhoA activity via $\mathrm{S}_{1} \mathrm{P}_{3}$, but stimulated, rather than inhibited, Rac activity and migration. Rho may be involved in migration and invasion inhibition through negatively regulating Rac, as in migration inhibition in CHO cells [14].

Metastasis is a temporo-spacially architectured multistep phenomenon that takes place in the context of host environment. Rho family GTPases and their extracellular regulators were implicated in transformation and invasive phenotypes [18], however, their roles in metastasis in vivo were largely unknown. B16 cells that are injected into mouse tail veins form multiple metastatic nodules in the lung two or three weeks later. We found that daily intraperitoneal injection of S1P reduced the number of metastatic nodules [27]. More interestingly, transient treatment of B16 cells with S1P just before the tail vein injection also effectively reduced he number of metastatic nodules, suggesting that S1P might inhibit very early steps of pulmonary metastasis including attachment to the pulmonary capillary endotelium. Adenovirus-mediated transient 
expression of $\mathrm{N}^{17}$ Rac markedly inhibited pulmonary metastasis, suggesting that Rac inhibition might underly S1P inhibition of metastasis. The stable overexpression of $\mathrm{S}_{1} \mathrm{P}_{2}$ augmented $\mathrm{S} 1 \mathrm{P}$-induced cell migration inhibition compared to vector control cells, whereas the overexpression of either $\mathrm{S}_{1} \mathrm{P}_{1}$ or $\mathrm{S}_{1} \mathrm{P}_{3}$ greatly attenuated $\mathrm{S} 1 \mathrm{P}$ inhibition of migration or stimulated migration. In $\mathrm{S}_{1} \mathrm{P}_{2}$-overexpressing cells $\mathrm{S} 1 \mathrm{P}$-induced metastasis inhibition was augmented. In contrast, that of either $\mathrm{S}_{1} \mathrm{P}_{1}$ or $\mathrm{S}_{1} \mathrm{P}_{3}$ resulted in aggravation of metastasis in an S1P-dependent manner. These observations suggest that Rac is required at a very early stage of hematogenous metastasis before invasion or proliferation and that G-protein-coupled receptors could participate in regulation of metastasis in receptor subtype-specific ligand-dependent manners.

\section{Differential regulation of Rac and cell migration by endogenous Edg} receptors in vascular smooth muscle and endothelial cells

As mentioned above, S1P displays unique bimodal activities on two vascular cell types, endothelial cells [10, 15] and VSMCs [28]. S1P inhibits VSMC migration, whereas it stimulates endothelial cell migration. Both VSMCs and endothelial cells in culture 
express multiple S1P receptor subtypes. VSMCs express abundant levels of $\mathrm{S}_{1} \mathrm{P}_{2}$ and $\mathrm{S}_{1} \mathrm{P}_{3}$, and endothelial cells express $\mathrm{S}_{1} \mathrm{P}_{1}$ and $\mathrm{S} 1 \mathrm{P}_{3}[28,29]$. The expression of $\mathrm{S}_{1} \mathrm{P}_{1}$ in VSMCs and $\mathrm{S}_{1} \mathrm{P}_{2}$ in endothelial cells is very faint. The observations, together with the fact that $\mathrm{S}_{1} \mathrm{P}_{1}$ and $\mathrm{S}_{1} \mathrm{P}_{3}$ are chemotactic whereas $\mathrm{S}_{1} \mathrm{P}_{2}$ is inhibitory, suggest that the vascular cell type-specific, distinct expression pattern of the S1P receptor subtypes can account for differential cell motility responses of the two vascular cell types. The S1P receptors exerted bimodal regulation on Rac activity in vascular cells; S1P inhibited PDGF-induced Rac activation in VSMCs although S1P alone did not affect Rac very much, whereas S1P by itself robustly stimulated Rac activity in endothelial cells. The overexpression of $\mathrm{S}_{1} \mathrm{P}_{1}$ in VSMCs rendered the cells chemotactic toward $\mathrm{S} 1 \mathrm{P}$ with elevation of Rac, whereas that of $\mathrm{S} \mathrm{P}_{2}$ augmented S1P inhibition of PDGF-directed chemotaxis. The overexpression of $\mathrm{S}_{1} \mathrm{P}_{1}$ in endothelial cells also made the cells repulsive in response to S1P. These observations are consistent with the notion that that an integration of the S1P receptor subtype-selective, positive and negative signals on cellular Rac activity is a critical determinant for eventual direction of regulation on cell motility by S1P. 


\section{Future directions}

The S1P receptors, especially $\mathrm{S}_{1} \mathrm{P}_{1}, \mathrm{~S}_{1} \mathrm{P}_{2}$ and $\mathrm{S} 1 \mathrm{P}_{3}$, are expressed widely in a variety of tissues during the fetal life as well as the adult life. Both attractive and repulsive signals guide migrating cells in tissue remodeling and angiogenesis as well as organogenesis and morphogenesis. It is likely that $\mathrm{S}_{1} \mathrm{P}_{2}$, a unique negative regulator of Rac, might be involved in these pathological and physiological processes in concert with $\mathrm{S}_{1} \mathrm{P}_{1}$ and $\mathrm{S}_{1} \mathrm{P}_{3}$, which are positive regulators of Rac, and presumably also other S1P receptors. It would be particularly interesting to see whether these S1P receptors play any role in pathological processes such as inflammation, tumor cell progression and atherosclerosis. Elucidation of pathological roles for the S1P signaling system is expected to lead to development of novel therapeutic strategies including the use of specific antagonists and agonists for S1P receptor subtypes and inhibitors of synthesis and degradation of S1P, and therefore should deserve intensive investigation.

\section{Refernces}


1. Yatomi Y, Ozaki Y, Ohmori T, Igarashi Y (2001) Sphingosine 1-phosphate: synthesis and release. Prostaglandins Other Lipid Mediat 64:107-122

2. Takuwa Y (2002) Subtype-specific differential regulation of Rho family G proteins and cell migration by the Edg family sphingosine-1-phosphate receptors. Biochim Biophys Acta 1582:112-120

3. Hla T, Lee MJ, Ancellin N, Paik JH, Kluk MJ (2001) Lysophospholipids-receptor revelations. Science 294:1875-1878

4. Ishii I, Fukushima N, Ye X, Chun J (2004) Lysophospholipid receptors: signaling and biology. Annu Rev Biochem 73:321-54

5. Spiegel S, Milstien S (2003) Sphingosine-1-phosphate: an enigmatic signalling lipid. Nat Rev Mol Cell Biol 4:397-407

6. Lauffenburger DA, Horwitz AF (1996) Cell migration: a physically integrated molecular process. Cell 84: 359-369

7. Sadahira Y, Ruan F, Hakomori S, Igarashi Y (1992) Sphingosine 1-phosphate, a specific endogenous signaling molecule controlling cell motility and tumor cell invasiveness. Proc Natl Acad Sci USA 89:9686-9690 
8. Bornfeldt KE, Graves LM, Raines EW, Igarashi Y, Wayman G, Yamamura S, Yatomi Y, Sidhu JS, Krebs EG, Hakomori S, Ross (1995) Sphingosine-1-phosphate inhibits PDGF-induced chemotaxis of human arterial smooth muscle cells: spatial and temporal modulation of PDGF chemotactic signal transduction. J Cell Biol 130:193-206 9.Kawa S, Kimura S, Hakomori S, Igarashi Y (1997) Inhibition of chemotactic motility and trans-endothelial migration of human neutrophils by sphingosine 1-phosphate. FEBS Lett 420:196-200

10. Lee MJ, Thangada S, Claffey KP, Ancellin N, Liu CH, Kluk M, Volpi M, Shaafi RI, Hla T (1999) Vascular endothelial cell adherens junction assembly and morphogenesis induced by sphingosine-1-phosphate. Cell 99:301-312

11. Liu Y, Wada R, Yamashita T, Mi Y, Deng CX, Hobson JP, Rosenfeldt HM, Nava VE, Chae SS, Lee MJ, Liu CH, Hla T, Spiegel S, Proia RL (2009) Edg-1, the G protein-coupled receptor for sphingosine-1-phosphate, is essential for vascular maturation. J Clin Invest 106:951-961

12. Yamamura S, Yatomi Y, Ruan F, Sweeney EA, Hakomori S, Igarashi Y (1997) Sphingosine 1-phosphate inhibits motility of human breast cancer cells independently of 
cell surface receptors. Biochemistry 36:10751-10759

13. Okamoto H, Takuwa N, Yokomizo T, Sugimoto N, Sakurada S, Shigematsu H, Takuwa, Y (2000) Inhibitory regulation of Rac activation, membrane ruffling, and cell migration by the G protein-coupled sphingosine-1-phosphate receptor EDG5 but not EDG1 or EDG3. Mol Cell Biol 20:9247-9261

14. Sugimoto, N., Takuwa, N., Okamoto, H., Sakurada, S., and Takuwa, Y. (2003) Inhibitory and stimulatory regulation of Rac and cell motility by the G12/13-Rho and Gi pathway integrated downstream of a single G protein-coupled sphingosine-1-phosphate receptor isoform. Mol. Cell. Biol. 23, 1534-1545

15. Wang F, Van Brocklyn JR, Hobson JP, Movafagh S, Zukowska-Grojec Z, Milsime S, Spiegel S. Sphingosine 1-phosphate stimulates cell migration through a G(i)-coupled cell surface receptor. Potential involvement in angiogenesis. J. Biol. Chem. 1999; 274: 35343-35350.

16. Hall, A. 1998. Rho GTPases and the actin cytoskeleton. Science. 279: 509-514

17. Nobes, C.D., and A.Hall. 1999. Rho GTPases control polarity, protrusion, and 
adhesion during cell movement. J. Cell. Biol. 144:1235-1244.

18. Banyard, J., B. Anand-Apte, M. Symons, and B.R.Zetter. 2000. Motility and invasion are differentially modulated by Rho family GTPases. Oncogene. 19:580-591. 19.Takuwa Y. (2002) Subtype-specific differential regulation of Rho family G proteins and cell migration by the Edg family sphingosine-1-phosphate receptors. Biochim Biophys Acta 1582: 112-120

20. Takuwa Y, Takuwa N, Sugimoto N. (2002) The Edg family G protein-coupled receptors for lysophospholipids: their signaling properties and biological activities. J Biochem 131: 767-771

21. Koch, W.J., B.E. Hawes, J. Inglese, L.M. Luttrell, and R.J. Lefkowitz. 1994. Cellular expression of the carboxyl terminus of a $G$ protein-coupled receptor kinase attenuates G beta gamma-mediated signaling. J. Biol. Chem. 269:6193-6197.

22. Seifert, R., K. Wenzel-Seifert, and B.K. Kobilka. 1999. GPCR-Galpha fusion proteins: molecular analysis of receptor-G-protein coupling. Trends Pharmacol. Sci. 20:383-9.

23. Sanchez T, Thangada S, Wu MT, Kontos CD, Wu D, Wu H, Hla T. (2005) PTEN as 
an effector in the signaling of antimigratory $G$ protein-coupled receptor. Proc Natl Acad Sci USA 102: 4312-4317.

24. F. Wang, J. R. Van Brockly, L. Edsall, V. E. Nava, S. Spiegel. (1999) Sphingosine-1-phosphate inhibits motility of human breast cancer cells independently of cell surface receptors. Cancer Res. 59 (1999) 6185-6191.

25. Arikawa K, Takuwa N, Yamaguchi H, Sugimoto N, Kitayama J, Nagawa H, Takehara K, Takuwa Y. (2003) Ligand-dependent inhibition of B16 melanoma cell migration and invasion via endogenous S1P2 G protein-coupled receptor. Requirement of inhibition of cellular Rac activity. J Biol Chem 278: 32841-32851

26. Zhuge Y, Xu J. (2001) Rac1 mediates type I collagen-dependent MMP-2 activation. role in cell invasion across collagen barrier. J Biol Chem 276: 16248-16256 27. Yamaguchi H, Kitayama J, Takuwa N, Arikawa K, Inoki I, Takehara K, Nagawa H, Takuwa Y. (2003) Sphingosine-1-phosphate receptor subtype-specific positive and negative regulation of Rac and hematogenous metastasis of melanoma cells. Biochem $\mathrm{J}$ 374: $715-722$

28. Ryu, Y., N. Takuwa, N. Sugimoto, S. Sakurada, S. Usui, H. Okamoto, O. Matsui and Y. 
Takuwa. 2002. Sphingosine-1-Phosphate, a Platelet-Derived Lysophospholipid Mediator, Negatively Regulates Cellular Rac Activity and Cell Migration in Vascular Smooth Muscle Cells. Circ. Res. 90: 325-332

29. S. Usui, N. Sugimoto, N. Takuwa, S. Sakagami, S. Takata, S. Kaneko, Y. Takuwa. (2004)Blood lipid mediator sphingosine-1-phosphate potently stimulates platelet derived growth factor-A and -B chain expression through S1P1-Gi-Ras-MAPK-dependent induction of krüppel-like factor 5. J. Biol. Chem. 279: $12300-12311$

Figure legend

Figure 1. Bimodal regulation of the Rho family GTPases and cell migration by the attractant receptors $\mathrm{S}_{1} \mathrm{P}_{1}$ and $\mathrm{S}_{1} \mathrm{P}_{3}$, and the repellent receptor $\mathrm{S}_{1} \mathrm{P}_{2} . \mathrm{S}_{1} \mathrm{P}_{1}$ and $\mathrm{S}_{1} \mathrm{P}_{3}$ mediate Rac activation and chemotaxis via Gi. S1P 2 mediates Rac inhibition and migration inhibition (chemorepulsion), which is mediated by G12/13 and Rho. $\mathrm{S}_{3} \mathrm{P}_{3}$ also stimulates Rho and generates an inhibitory signal for Rac, which is uncovered by inactivation of $\mathrm{Gi}$ with pertussis toxin. 

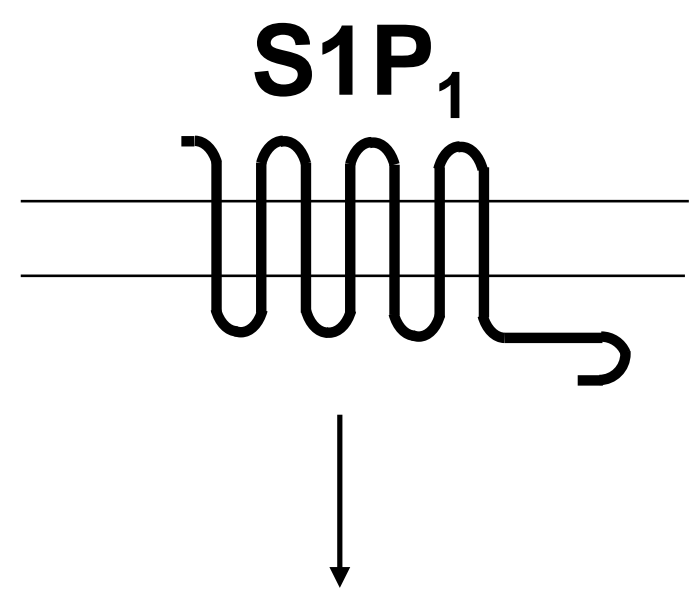

$\mathbf{G}_{\mathbf{i}}$

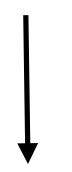

$\operatorname{Rac} \uparrow$

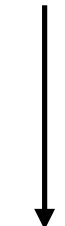

Chemotaxis
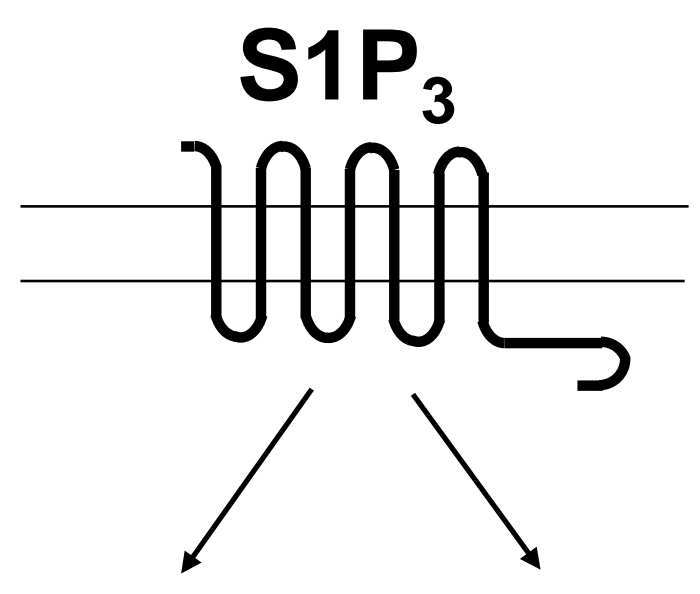

$\mathbf{G}_{\mathbf{i}}$

$\mathbf{G}_{12 / 13}$
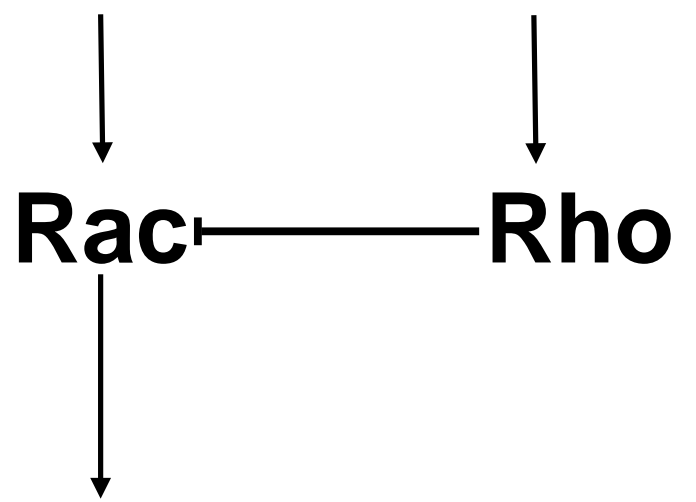

Chemotaxis

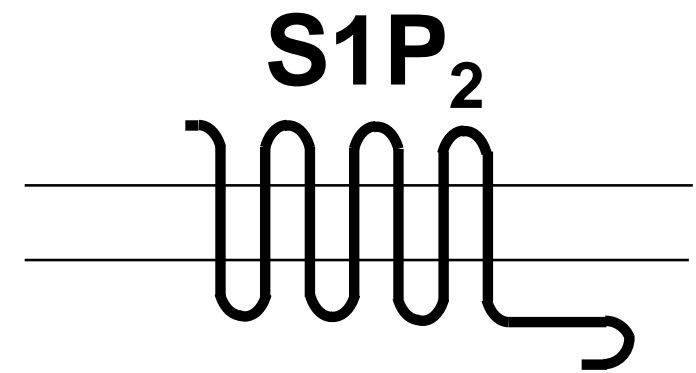

$\downarrow$

$\mathbf{G}_{12 / 13}$

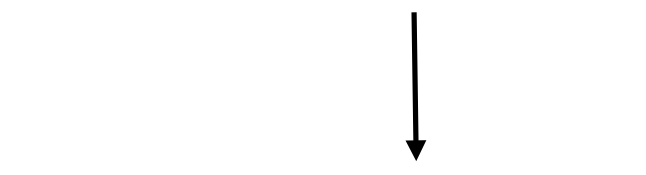

Rac - Rho

Chemorepulsion

Figure 1 